\title{
The SARS-CoV-2 Pandemic in Latin America: the Need for Multidisciplinary Approaches
}

\author{
Diana Callejas $^{1}$ (1) · José M Echevarría ${ }^{2} \cdot$ Yenddy Carrero $^{3} \cdot$ Alfonso J. Rodríguez-Morales $^{4,5} \cdot$ Ruth Moreira $^{6}$
}

Accepted: 27 October 2020

(C) Springer Nature Switzerland AG 2020

\begin{abstract}
Purpose of Review Acute respiratory infections of viral etiology (ARIVE) constitute one of the most frequent infectious processes among humans. They cause significant morbidity and mortality every year in all age groups and regions of the world. Their etiology is diverse, and seasonal viruses began their journey, at some point, with an episode of expansion before their annual circulation as seasonal agents. The coronavirus disease 2019 (COVID-19) pandemic is a challenge for Latin America. Understanding dynamics is essential for decision making, to reduce the health, economic, and social impacts of the pandemic. Recent Findings Currently, governments in Latin America have taken measures to mitigate the spread of COVID-19 primarily based on World Health Organization recommendations. However, the potential impact of the virus in Latin America is still unknown. Given the urgency, governments need more accurate estimates of what could happen in Latin America in order to make informed decisions, At the September 20, 2020, cumulative cases 2295 of COVID-19 per 1 million population has been registered in Latin America and the Caribbean. Brazil, Peru, and Chile are the most countries affected by this pandemic, registering a total of cumulative cases per million inhabitants of 21,148, 22,941, and 23,262 respectively. Peru has shown the highest death numbers with 949 per million inhabitants.

Summary The Latin American health authorities should make the most beneficial decisions based in scientific facts for the health and life of citizens, both understood in the broadest and most inclusive sense.

Once the epidemic is over, Latin America should begin a profound health reform, at a single and universal health system, integrated and coordinated, where the leading role of the Ministry of Health is resumed, to have a national network of modern, integrated, and excellent quality laboratories for the benefit of the entire society.
\end{abstract}

Keywords SARS-CoV-2 $\cdot$ COVID-19 $\cdot$ Coronavirus $\cdot$ Acute respiratory infection $\cdot$ Pneumonia $\cdot$ Pandemic $\cdot$ And Latin America

This article is part of the Topical Collection on COVID-19 in the Tropics: Impact and Solutions

Diana Callejas

callejas.diana60@gmail.com

1 Facultad de Ciencias de la Salud, Universidad Técnica de Manabí, Portoviejo, Manabí, Ecuador

2 Facultad de Biología, Universidad Complutense, Madrid, Spain

3 Facultad de Ciencias de la Salud, Carrera de Medicina, Universidad Técnica de Ambato, Ambato, Ecuador

4 Grupo de Investigación en Salud Pública e Infecciones, Facultad de Ciencias de la Salud, Universidad Tecnológica de Pereira, Risaralda, Colombia

5 Grupo de Investigación en Biomedicina, Facultad de Medicina, Fundación Universitaria Autónoma de las Américas, Pereira, Risaralda, Colombia

6 Facultad de Ciencias Médicas, Carrera de Medicina, Universidad Laica Eloy Alfaro de Manabí, Manta, Manabí, Ecuador

\section{Introduction}

Severe acute respiratory syndrome coronavirus 2 (SARS-CoV2) represents one of six types of human coronaviruses identified until now: NL63 and 229E belong to the alpha-coronavirus genus, and OC43, HKU1, SARS-CoV, and MERS-CoV to the genus beta-coronavirus ( [1]). None of them was very relevant until the 2003 Acute and Severe Respiratory Syndrome (SARS) pandemic, caused by SARS-CoV, which was followed 9 years after the appearance of the Middle East Respiratory Syndrome (MERS), due to MERS-CoV. These last two agents are highly pathogenic ( [2]). SARS-CoV disappeared a few months after emerging and has not been detected again, while MERS-CoV is still present but is not transmitted between humans. It remains quite restricted to its region of origin, producing sporadic cases, from reservoirs, depending on the place. Bats are a reservoir for many very diverse viruses, including coronaviruses $[3,4]$. We are currently witnessing the pandemic 
expansion of a new human coronavirus named by the World Health Organization (WHO) as COVID-19. However, the International Committee on Virus Taxonomy has been proposed to be nominated as SARS-CoV- [2] based on its degree of genetic similarity to SARS-CoV, which would now be renamed SARS-CoV- [2] caused an outbreak of severe acute respiratory infection (SARI), with moderate frequency of pneumonia, that started in December 2019 in Wuhan City, Hubei Province, Central China ( $[5,6])$. Epidemiologically and clinically, SARS-CoV- [2] behaves like a classic respiratory virus; however, the clinical manifestations involving several organs with high mortality make the difference. The COVID-19 lethality is between four and six times higher than that estimated for influenza in Spain [7]. A total of 31.7 million cases have been registered worldwide with 973,000 deaths; the global death to case ratio is $3.1 \%$. The USA, Peru, and Brazil are the most affected with an effective reproductive number (Rt) 5.8, 2.4, and 2.2 respectively [8].

Like any other respiratory virus, SARS-CoV-2 is transmitted primarily through respiratory droplets that are produced when an infected person coughs or sneezes (Flügge droplets). The virus can also infect the conjunctiva through the classic mechanism of transmission by fomites (from a contaminated surface to hands and then to the eyes). The transmission of the virus by aerosols in the community must be carefully considered in the healthcare setting. The course of the infection will then come highly conditioned by the age of the patient and by his previous state of health, with the critical exception that this virus appears in children under 5 years of age, who are more susceptible for flu in all the seasons [9]. The average number of new infections generated by a person infected with SARS$\mathrm{CoV}-2$ (R0) is estimated between 2.2 and 3.6; that is, each infected person would be a source of infection for between 2 and 4 susceptible people [10].

Following its epidemic emergency in Wuhan, the virus quickly reached other regions of Asia and the Western Pacific. A little later, it established two secondary outbreaks of diffusion to the west: the first in Iran (distribution towards the Middle East and
Egypt) and the second in Italy (spread towards Western Europe and America), Very soon after, the epidemic grew in Spain, Switzerland, the Netherlands, Austria, Belgium, and Germany. Later the epidemic appeared in the American continent focusing on New York with later presence of this viral infection in Latin America. Consequently, the center of gravity of the pandemic shifted clearly to Western Europe, and its emergence in America began to gain strength in the north [11].

The presence of the new coronavirus in Latin America was first documented on February 25, 2020, when the Brazilian Ministry of Health confirmed the detection of the first imported case. In the following weeks, it reached all the countries of the region. From infected travelers from Europe, mainly from Italy ( [12]), the virus managed to establish local transmission in almost all Latin American countries (as of March 21, only El Salvador and Nicaragua were exceptions). As for the Caribbean region, as of March 21, local transmission was recorded in all the Greater Antilles except Puerto Rico. However, no American country, including the USA, was yet close to the threshold of 50 cases $/ 100,000 \mathrm{~h}$ as of March 27. Ecuador was then the second country in terms of absolute number of confirmed cases, with an incidence of 9.21 cases $/ 100,000 \mathrm{~h}$. A total of 1595 cases had been accumulated in all the provinces (Tungurahua and Cotopaxi were the last to join), and 36 deaths were counted [13]. At present, September 23, 2020, in Ecuador, 129,892 cases and a total of 11,171 deaths are reported, with Pichincha and Guayas are the most affected provinces.

Due to the variability of epidemiological programs in European countries, the pandemic represents a tough challenge. In Latin America during July, in Chile, the incidence reached a higher figure to any other that has been registered in other countries. Despite accounting for more than 1.4 million cases, the rate shown by Brazil is lower than those registered in Chile, Peru, and Panama, which highlights the importance of never handling absolute figures when making a comparative assessment of the course of the epidemic, since its behavior has been heterogeneous (Fig. 1).
Fig. 1 WHO.2020. Available: https://www.who.int/docs/ default-source/coronaviruse/ situation-reports/20200921weekly-epi-update-6.pdf?sfvrsn= d9cf9496_6. Number of COVID19 cases and deaths reported weekly by the WHO Region of the Americas, as of 20 September 2020. The Region of the Americas remains the most affected WHO Region, accounting for $50 \%$ of all reported cases and $55 \%$ of deaths

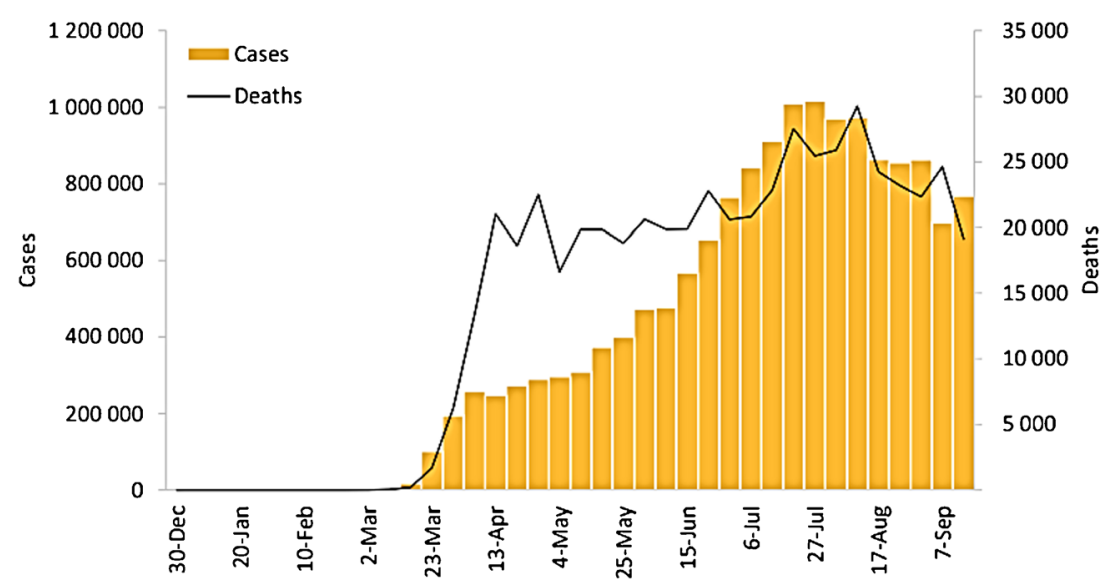


As usual in the series, the case fatality rate shows a wide variation that goes from $0.46 \%$ in Costa Rica to $12.28 \%$ in Mexico. At first glance, there are no obvious correlations between the accumulated incidences and parameters such as those related to the climate, geographical characteristics or population peculiarities, but these correlations can only be studied well when seroepidemiological surveys allow a better approximation of the real figures from infected people. These corrections are likely to revise case fatality rates well downward and significantly reduce differences between countries.

Consequently, Latin American government and academic institutions should focus their efforts on revealing the behavior of SARS-CoV-2 in the different environments and populations of a region whose ecological diversity ranges from the dry, humid, and rainy forests of the equatorial and tropical latitudes, to the glaciers of Patagonia, passing through the deserts of the highlands, through the pampas, through the plains and mountains of temperate climates, along the banks of immense rivers and along the coasts of two oceans, and from small rural towns to populous cities that count their inhabitants by the millions. The impact of this extremely complex environmental and human reality, vital for the behavior of an agent like this, cannot be learned from Europe, North America, or China. Active research must be carried out in the field so that the knowledge derived from the investigations is useful in designing successful and effective preventive strategies. Therefore, public and private support for scientific research, both basic and health, is essential currently.

\section{SARS-CoV-2 Pandemic in Latin America}

The 2019 Coronavirus Disease Pandemic (COVID-19) has put a great deal of pressure on critical healthcare systems. Since its beginnings in Asia, the largest growth in cases is currently in the Americas, with South American countries facing a strong challenge due to the vulnerability of their health systems and the socioeconomic conditions of their population.

COVID-19 is attacking the American continent; the USA has become the locus of the pandemic, with Brazil, Peru, Ecuador, Argentina, Mexico, and Chile among the most affected countries. It is nearly impossible to keep up to date with the pandemic's statistics, and as of September 23, 2020, according to the Johns Hopkins University Coronavirus Resource Center, confirmed cases in the USA total $6,943,078$ people and 201,930 deaths, while Canada has 149,939 cases and 9294 deaths.

The coronavirus entered Latin America on February 26, when Brazil confirmed the first case in São Paulo, and the first death from the infection in the region was announced in Argentina on March 7. Since then, governments throughout the region have taken a series of measures to protect their citizens and contain the spread of COVID-19. Today, Latin America and the Caribbean become the region with the most confirmed cases globally, accounting for more than a quarter of the world's cases (see Table 1) representing $13.07 \%$ of the total number of cases reported worldwide. The Latin American country is the most affected by COVID-19, and the new focus of the pandemic in the region is Brazil, with more than 121,515 deaths and more than 3,910,901 cases of contagion. Meanwhile, the number of cases and deaths (respectively) are as follows: Mexico: 599,560 and 64,414; Peru: 28,944 and 65,203; Chile: 411,726 and 11,289; Ecuador: 113,767 and 6556; and Bolivia: 116,598 and 5027. The situation in Ecuador, particularly the city of Guayaquil and now its capital Quito, has been particularly dire due to the rapid saturation and collapse of the country's health system. Peru was one of the first countries to impose restrictions in addition to generating aid packages for people affected by the suspension of the economy; months later, Peru began to report high figures of infections, perhaps due to the deficiency of the quarantine and the sharp decline in the economy, and after more than 5 months have passed. Peru has the highest mortality from COVID-19. Of the 20 most affected countries according to a report by Johns Hopkins University, Peru has 87.53 deaths per 100,000 inhabitants, placing it ahead of countries such as the USA, Brazil, and Mexico. In Central America, Panama is the country most affected by the pandemic, followed by Honduras, Guatemala, El Salvador, Costa Rica, and Nicaragua. In the Caribbean, the Dominican Republic is the most affected country, followed by Cuba [14].

The fact that SARS COV-2 arrived in Latin America much later than in Asia and Europe, allowed these countries to take strong containment measures in time to curb the epidemic by promoting stricter hygiene measures; this included search and contact of suspected cases; restrictions on mobility and crowding in the streets; closure of schools and universities, food outlets, bars, restaurants, shops, and malls; voluntary or mandatory quarantine; night curfews; border closures; suspension of international flights; mandatory use of protective masks for the general population; and suspension of public transportation, all with the purpose of making rational use of available economic resources in public health. Despite these measures, Latin America is in an epidemiological emergency and presents many deaths. But keeping a largely income-dependent population in prolonged quarantine is difficult; even though without quarantine and social isolation, transmission rates will be very high, and the duration of the pandemic could be extended. The total or partial nonimplementation of strict quarantine protocols, with restrictions on mobility, social interaction, and even work activities, would generate increased demand for consultation at all levels of care, especially in emergency services due to fear and ignorance of the situation [15]. 
Table 1 Cumulative confirmed and probable COVID-19 cases reported by Countries and Territories in the Region of the Americas. 01 September 2020

\begin{tabular}{|c|c|c|c|c|c|}
\hline Subregion & Country/Territory & Transmission Type & Cases & Deaths & Recovered \\
\hline \multirow[t]{4}{*}{ North America } & Canada & Community & 127,940 & 9117 & 113,664 \\
\hline & Mexico & Community & 595,841 & 64,158 & 412,580 \\
\hline & USA & Community & $5,936,572$ & 182,162 & $2,152,529$ \\
\hline & Total & & $6,660,353$ & 255,437 & $2,678,773$ \\
\hline \multirow[t]{8}{*}{ Central America } & Belize & Community & 993 & 13 & 117 \\
\hline & Costa Rica & Community & 39,699 & 418 & 15,737 \\
\hline & El Salvador & Community & 25,729 & 717 & 14,292 \\
\hline & Guatemala & Community & 74,074 & 2,760 & 62,068 \\
\hline & Honduras & Community & 60,174 & 1,858 & 10,242 \\
\hline & Nicaragua & Community & 3659 & 137 & 3339 \\
\hline & Panama & Community & 92,065 & 1,995 & 65,747 \\
\hline & Total & & 296,393 & 7898 & 171,542 \\
\hline \multirow[t]{11}{*}{ South America } & Argentina & Community & 417,735 & 8730 & 308,376 \\
\hline & Bolivia (Plurinational State of) & Community & 115,968 & 4966 & 58,497 \\
\hline & Brazil & Community & $3,862,311$ & 120,828 & $3,031,626$ \\
\hline & Chile & Community & 411,726 & 11,289 & 383,879 \\
\hline & Colombia & Community & 607,938 & 19,364 & 450,621 \\
\hline & Ecuador & Community & 113,767 & 6556 & 86,252 \\
\hline & Paraguay & Community & 17,105 & 308 & 9146 \\
\hline & Peru & Community & 647,166 & 28,788 & 455,457 \\
\hline & Uruguay & Clusters & 1585 & 44 & 1378 \\
\hline & Venezuela (Bolivarian Republic of) & Community & 46,728 & 386 & 38,112 \\
\hline & Total & & $6,242,029$ & 201,259 & $4,823,344$ \\
\hline \multirow[t]{25}{*}{ Caribbean and Atlantic Ocean Islands } & Anguilla & No cases & 3 & 0 & 3 \\
\hline & Antigua and Barbuda & Clusters & 94 & 3 & 91 \\
\hline & Aruba & Community & 1997 & 10 & 765 \\
\hline & Bahamas & Clusters & 2167 & 43 & 782 \\
\hline & Barbados & Clusters & 173 & 7 & 145 \\
\hline & Bermuda & Sporadic & 169 & 9 & 153 \\
\hline & Bonaire, Sint Eustatius and Saba & Sporadic & 16 & 0 & 12 \\
\hline & British Virgin Islands & Clusters & 47 & 1 & 8 \\
\hline & Cayman Islands & Sporadic & 205 & 1 & 202 \\
\hline & Cuba & Clusters & 4032 & 94 & 3378 \\
\hline & Curacao & Clusters & 68 & 1 & 35 \\
\hline & Dominica & Clusters & 20 & 0 & 18 \\
\hline & Dominican Republic & Community & 94,715 & 1710 & 68,082 \\
\hline & Falkland Islands (Malvinas) & No cases & 13 & 0 & 13 \\
\hline & French Guiana & Community & 9115 & 59 & 8654 \\
\hline & Grenada & Clusters & 24 & 0 & 24 \\
\hline & Guadeloupe & Clusters & 1145 & 16 & 336 \\
\hline & Guyana & Clusters & 1234 & 37 & 687 \\
\hline & Haiti & Community & 8224 & 201 & 5828 \\
\hline & Jamaica & Clusters & 2357 & 21 & 890 \\
\hline & Martinique & Clusters & 596 & 16 & 98 \\
\hline & Montserrat & No cases & 13 & 1 & 9 \\
\hline & Puerto Rico & Community & 33,199 & 434 & 0 \\
\hline & Saint Barthelemy & Sporadic & 18 & 0 & 13 \\
\hline & Saint Kitts and Nevis & No cases & 17 & 0 & 17 \\
\hline
\end{tabular}


Table 1 (continued)

\begin{tabular}{|c|c|c|c|c|c|}
\hline Subregion & Country/Territory & Transmission Type & Cases & Deaths & Recovered \\
\hline & Saint Lucia & Sporadic & 26 & 0 & 25 \\
\hline & Saint Martin & Sporadic & 213 & 5 & 79 \\
\hline & Saint Pierre and Miquelon & Sporadic & 5 & 0 & 4 \\
\hline & Saint Vincent and the Grenadines & Sporadic & 60 & 0 & 57 \\
\hline & Sint Maarten & Community & 463 & 17 & 179 \\
\hline & Suriname & Community & 4009 & 67 & 3073 \\
\hline & Trinidad and Tobago & Community & 1727 & 22 & 676 \\
\hline & Turks and CAICOS ISLANDS & Clusters & 507 & 3 & 200 \\
\hline & United States Virgin Islands & Community & 1134 & 14 & 898 \\
\hline & Total & & 167,805 & 2792 & 95,434 \\
\hline Grand total & & & $13,366,580$ & 467,386 & $7,769,093$ \\
\hline
\end{tabular}

Paho, 2020. Available: https://www.paho.org/es/temas/coronavirus/brote-enfermedad-por-coronavirus-covid-19 112,489 cases and 2162 additional deaths were reported in the last $24 \mathrm{~h}$, representing relative increase of $0.84 \%$ in cases and a relative increase of $0.46 \%$ in deaths, compared to the previous day

Facing a public health problem of such magnitude in a scenario of limited economic resources compromises the application of adequate prevention strategies, including the necessary large-scale implementation of rapid diagnostic tests, which is of vital importance for tracking the virus, understanding local epidemiology, and suppressing transmission, in addition to adequate compliance with outpatient and inpatient treatment protocols [16].

In a relatively short period of time, the SARS-CoV-2 pandemic has been characterized by three distinctive features; the first, the speed of spread and scale of infection, causing a collapse and saturation of health systems worldwide; second, the severity and lethality According to WHO, 20\% of cases are serious or critical, and the crude death rate currently exceeds $3 \%$, and has a higher incidence in older population groups and with previous conditions or ailments. Finally, social and economic disruption, causing various disorders in the health and health systems of all countries and at the same time, as the various measures of self-isolation and social distancing adopted to control transmission and the rate of contagion continue to have profound economic and social consequences for both developed and emerging economies [17].

At the global level, and as transmission of SARS-CoV-2 continues to advance, the main objective of the health systems of many countries in the world, and currently in Latin America and the Caribbean, is the adoption of an epidemiological surveillance model adapted to the conditions of each country that will make it possible to reduce the infection curve that is normally bell-shaped [18].

The model is based mainly on the identification and tracking of infected people, testing and treatment, and rapid response of severe patients as well as the protection of people at greatest risk and vulnerability. In any case, the aim is to stop the explosive outbreak of the epidemic and to accompany it with measures of isolation and confinement, which as we know, have been very drastic and severe in some countries and in others, more lax and permissive [18].

Finally, it is important to recommend that emergency public health policies of international importance be strengthened in the region, with drills in all countries, and that work on territorial borders be reinforced to identify risk factors through targeted surveys, and that patients be identified and monitored from international migration posts, in compliance with international health standards.

\section{Conclusion}

The most important public health policy lesson that can be highlighted to date, based on the global response to COVID19, has been that in order to contain the transmission and spread of this disease, it is essential that public health specialists, epidemiologists, and health personnel in general have the support of their governments to diagnose and track all cases of COVID-19, isolate them and provide them with the required medical care. Ideally, this should be done in a controlled healthcare environment or in the home, taking into consideration the particular context of each country and the severity or seriousness of the disease. It is important to monitor the diagnostic methods, unregistered of cases, the immunity developed by the patients, circulating strains, the health protocols, and the future application of the vaccine, as well as taking the experience of Europe, the flexibility and the regrowth in order to minimize the impact of SARS-CoV-2 in Latin America. 


\section{References}

1. Tang Q, Song Y, Shi M, Cheng Y, Zhang W, et al. Inferring the hosts of coronavirus using dual statistical models based on nucleotide composition. Sci Rep. 2015;5:17155.

2. Cui J, Li F, Shi ZL. Origin and evolution of pathogenic coronaviruses. Nat Rev Microbiol. 2019;17(3):181-92. https:// doi.org/10.1038/s41579-018-0118-9.

3. Woo PCY, Lau SKP. Viruses and bats. Viruses. 2019;11:884-7. https://doi.org/10.3390/v11100884.

4. Banerjee A, Kulksar K, Misra V, Frieman M, Mossman K. Bats and coronaviruses. Viruses. 2019;11:41-56. https://doi.org/10.3390/ v11010041.

5. Huang C, Wang Y, Li X, Ren L, Zhao J, Hu Y, et al. Clinical features of patients infected with 2019 novel coronavirus in Wuhan. Lancet. 2020;395(10223):497-506. https://doi.org/10. 1016/S0140-6736(20)30183-5.

6. Zhou P, Yang XL, Wang XG, Hu B, Zhang L, Zhang W, et al. A pneumonia outbreak associated with a new coronavirus of probable bat origin. Nature. 2020;579(7798):270-3. https://doi.org/10.1038/ s41586-020-2012-7.

7. Centro Nacional de Epidemiología. Informe sobre situación del CoVID19 en España. No.17. 2019.

8. PAHO. Evolution of the effective reproductive number and cases based on the date of report. 2020. Available: http://ais.paho.org/ phip/viz/COVID19Rt.asp

9. Centro Nacional de Epidemiología. Informe de vigilancia de la gripe en España. Temporada 2018-2019.

10. Read JM et al. Novel coronavirus 2019-nCoV: early estimation of epidemiological parameters and epidemic predictions 1 Novel coronavirus 2019-nCoV: early estimation of epidemiological parameters and epidemic predictions. Medrxiv. 2020. https://doi.org/10. 1101/2020.01.23.20018549.
11. OMS COVID-19. Timeline of WHO action. 2020.Available: https://www.who.int/es/news-room/detail/27-04-2020-whotimeline\%2D\%2D-covid-19.

12. Caicedo-Ochoa Y, Rebellón-Sánchez DE, Peñaloza-Rallón $M$, Cortés-Motta HF, Méndez-Fandiño YR. Estimación efectiva del número reproductivo para la etapa inicial de la pandemia de COVID-19 en países de América Latina. Int J Infect Dis. 2020;95:316-8. https://doi.org/10.1016/j.ijid.2020.04.069.

13. Dunlop C, Howe A, Li D, Allen LN. The coronavirus outbreak: the central role of primary care in emergency preparedness and response. BJGP Open. 2020;4(1):bjgpopen20X101041. Published 2020 May 1. https://doi.org/10.3399/bjgpopen20X101041.

14. PAHO. COVID-19 Situation in the Region of the Americas. September 1st, 2020 15:00 (EST). Available: https://www.paho. org/en/topics/coronavirus-infections/coronavirus-disease-covid19-pandemic

15. Institute of Medicine (US) Forum on Microbial Threats. Ethical and legal considerations in mitigating pandemic disease: workshop summary. Washington (DC): National Academies Press (US); 2007. 3, Strategies for Disease Containment. Available from: https://www.ncbi.nlm.nih.gov/books/NBK54163/

16. Pierre ÁR, Harris Paul R. COVID-19 en América Latina: Retos y oportunidades. Rev Chil Pediatr. 2020;91(2):179-82. https://doi. org/10.32641/rchped.vi91i2.2157.

17. (WHO) (OMS, 2020). Actualización de la estrategia frente a la covid-19. organización mundial de la salud.

18. Gourinchas. flattening the pandemic and recession curves. en $r$. baldwin, \& b. w. (eds.), mitigating the covid economic crisis: act fast and do whatever it takes. Cepr. 2020. (pag. 31-39). Available: https://voxeu.org/article/flattening-pandemic-and-recession-curves

Publisher's Note Springer Nature remains neutral with regard to jurisdictional claims in published maps and institutional affiliations. 